\title{
Web Service Testing Techniques: A Systematic Literature Review
}

\author{
Israr Ghani ${ }^{1}$, Wan M.N. Wan-Kadir ${ }^{2}$, Ahmad Mustafa ${ }^{3}$ \\ School of Computing, Faculty of Engineering, Universiti Teknologi Malaysia \\ Skudai, Johor Bahru, 81310, Malaysia
}

\begin{abstract}
These days continual demands on loosely coupled systems have web service gives basic necessities to deliver resolution that are adaptable and sufficient to be work at runtime for maintaining the high quality of the system. One of the basic techniques to evaluate the quality of such systems is through testing. Due to the rapid popularization of web service, which is progressing and continuously increasing, testing of web service has become a basic necessity to maintain high quality of web service. The testing of the performance of Web service based applications is attracting extensive attention. In order to evaluate the performance of web services, it is essential to evaluate the QoS (Quality of Service) attributes such as interoperability, reusability, auditability, maintainability, accuracy and performance to improve the quality of service. The purpose of this study is to introduce the systematic literature review of web services testing techniques to evaluate the QoS attributes to make the testing technique better. With the intention of better testing quality in web services, this systematic literature review intends to evaluate what QoS parameters are necessary to provide better quality assurance. The focus of systematic literature is also to make sure that quality of testing can be encouraged for the present and future. Consequently, the main attention and motivation of the study is to provide an overview of recent research efforts of web service testing techniques from the research community. Each testing technique in web services has identified apparent standards, benefits, and restrictions. This systemic literature review provides a different testing resolution to industry to decide which testing technique is the most efficient and effective with the testing assignment agenda with available resources. As for the significance, it can be said that web service testing technique are still broadly open for improvements.
\end{abstract}

Keywords-Quality assurance; web service testing; web service testing techniques; web service component testing

\section{INTRODUCTION}

Web services are growing in popularity in the software industry [1]. In order to achieve higher success rates several testing models, frameworks, tools, and techniques have been proposed and widely used where testing plays an important role to maintain the high quality of web services. However, it remains a challenging task to test web services, whether the type is SOAP (Simple Object Access Protocol) or REST (Representational State Transfer). Since there is a wide range of challenges, a comprehensive systemic literature review is presented to observe what the critical challenges are, with a focus on quality attributes and existing solutions to resolve the testing issues in web services.
Web services and micro services are software system. Both web services and micro services are utilized for coordination of various web applications using specific measures. Web services have advanced to the point that minimal effort is required for conveying information that is isolated between platforms and applications running on different functional systems and languages. Web services can be classified into two types: web service utilized in the intranet and the Internet. Web service given by the intranet is restricted to inside the concerned organization and is not accessible to the general public, while web services over the internet are available for all to utilize.

The benefit of intranet web service is that it is safe as the organization has full control. One benefit is that the service is only available to internal clients. With an internet web service, security [2-4] performance $[3,5,6]$ efficiency $[7,8]$ reliability, interoperability [9] and accuracy $[8,10]$ need more concentration in order to obtain successful test rating. Mentioned parameters have become leading issues in web service testing due to its distinctive scalability [11] and confidentiality concerns.

Furthermore, real challenging task [12-14] in web service testing domain is that it has no Graphic User Interface (GUI) [15]. Thus, web service has no GUI to be verified and tested. Therefore, testing analysers involve some development capabilities and explicit tools [9, 16], framework [17-19], model $[6,11,17,20]$ or calculations to test GUI in web services. To put it plainly, testing of web services is not a straightforward job to be completed and require extraordinary capabilities, skills and innovation. Many tools, frameworks, approaches [20] and models have been introduced to improve web service testing. As a result, a few methodologies [10, 21, 22] are recommended to examine the nature of these techniques and tools. This research depends on essential analysis of two testing approaches: black box [23, 24] and white box [24] to test web service [25]. Current studies [8, 2629] proposed techniques [8, 28, 29] and approaches for web service testing and produced an assessment to execute in order to obtain expected results.

For that reason, this study highlights those parameters which are not viably taken care of in these testing techniques. The results of the comparison between the primary studies will indicate [30] increasingly proficient testing strategies.

With the expectation of better testing quality in web service, this study presents an overview of testing techniques to assess which QoS parameters are important to give better 
quality affirmation. The focus of this study is to ensure that nature of testing can be encouraged from the present and future perspectives. Therefore, the primary consideration and inspiration of the study is to explore the related test techniques and provide an overview of the recent research in web service testing.

\section{RELATED WORK}

AL Lemos and G Fraser [31, 32] also introduce the testing techniques to improve the quality of web service testing. This study introduces several testing approaches, models and tools to improve the web service quality better according to the industry requirements. In our primary study, we introduce 20 most used and trending testing techniques of web services where some authors suggested models and framework [7, 9, 11]. R. Casado and Z. U. Singhera [10, 33] present tools and frameworks against quality attributes such as performance interoperability, maintainability, reusability, efficiency and reliability. Jamshidi and Pooyan Pahl, Claus [34] explained different techniques and framework for SOA based service testing and mentioned how the service quality can be improved further.

\section{RESEARCH METHOD AND MOTIVATION}

In order to conduct a comprehensive analysis on testing of web service, we have defined research questions in Table I after analysis of selected primary study from Table I to Table IV stepwise.

Different models, approaches, frameworks and tools to recommend a resolution for web service testing have been described by most studies. These models and frameworks and tools have additional overhead and are not sufficient on multiple and different platforms while testing web service[34]. It has been observed that for multi dimension platforms, there are essential requirements for web service testing teams to work in this way [35]. In order to incorporate industry level web service testing, a comprehensive resolution[36] should be recommended to get the expected results.

The bottleneck in web service testing is the maturity of the exclusive parameters like reusability, performance, security, interoperability, maintenance, reliability and efficiency [37, 38]. Non-functional requirement (NFR) in web service testing [33] is neglected in previous literature reviews because of the nature of web service testing process [39]. There is a need for more empirical research in this area.

TABLE. I. RESEARCH QUESTIONS

\begin{tabular}{|l|l|}
\hline $\begin{array}{l}\text { Research Question } \\
\text { (RQ) }\end{array}$ & Question Statement \\
\hline RQ1 & What are the issues in testing web services? \\
\hline RQ2 & $\begin{array}{l}\text { What are the quality related aspects and concerns } \\
\text { with respect to testing of web services? }\end{array}$ \\
\hline RQ3 & $\begin{array}{l}\text { What are the existing solutions to solve the web } \\
\text { services testing issues? }\end{array}$ \\
\hline RQ4 & How were existing testing techniques applied? \\
\hline
\end{tabular}

Some authors and studies have discussed automation of web service testing as an advantage of web service testing; some studies [40] suggest different automation testing techniques using tools and frameworks for web service testing. There is a lack of comprehensive research in the study for automation in web service testing. There is a need for more research and study to perform some extra investigation with an automation type of testing in web service. Based on the most common issues [41] and quality aspects according to the primary study, study and experiments of testing should focus on interoperability, performance, reliability and efficiency regarding the control of different testing techniques.

Existing tools and approaches $[42,43]$ are not sufficient to reveal structural errors to test web service [44]. This has motivated us to go through the literature and analyse the web service testing with respect to SOAP and RESTful and has led to the following research questions.

\section{A. Research Questions}

The primary interest of researcher is to identify the scope of future research activities for testing of web services. This systematic review identified the research study to make it more prominent for suggested study. Based on selected primary studies, the following research questions has been raised to make the web service testing techniques more effective and useful for the industry as well as for future researchers.

Following are the inclusion and exclusion criteria driving the research questions generated after selection of primary study.

\section{B. Inclusion Study Standards}

The criteria for inclusion of study are:

- Papers published from 2010 to 2019.

- Search regarding web service testing SOAP and RESTful.

- Search for papers that address specific testing problems in Document style XML and RPC.

- Search for papers that offer practical support for web service SOAP and RESTful testing technique.

- Papers that have quality related aspects and concerns with respect to web service quality assurance.

Studies selected in order to solve the web service testing issues.

\section{Exclusion Study Criteria}

The following steps are taken to exclude papers from primary study:

- Studies published before 2010.

- Research papers that not relevant to web service quality assurance.

- Title based research material that is problematic to classify is based on title search and referring to next step. 
- After reading the abstract, the articles are identified as duplicate.

\section{Study Selection Approach}

In the selection of survey procedure, web service testing based work has been selected. Initially, digital databases are explored i.e. " 'Science Direct', 'ACM Library', 'IEEE Xplore', 'ISI Web of Science', 'Springer Link', 'Scopus' and 'Wiley'”.

In order to get desired results, manual search has also been executed in different sources corresponding to items of the scientific databases. To find the appropriate research studies that are not available in main database, Google Scholar was primarily used as a Meta - engine. Search for selected study was restricted to papers published between 2010 and 2019. As a result of initial queries, we obtained 674 published papers regarding web service testing techniques from 2010 to 2019 .

Most of the sources contain important journals, symposiums, and workshop and conference proceedings within the web service domain. Search terms are mentioned in Table II. The queries were executed on different characteristics depending on the available options in database.

In primary study selection criteria, we make sure that published papers that were associated to web service testing techniques were included in search goal.

The search study is being extended instead of imperfect using the option (OR) web service AND testing, meaning that we submitted this search string in seven scientific databases as shown in Table III.

According to the provided information, the selected study was limited to the title, abstract, keyword to ensure that the results of the search string are appropriate in the context of the study.

Most of the sources include important journals, symposiums, and workshop and conference proceedings within the web service domain. Search terms are mentioned in Table II. The queries were executed on different characteristics depending on the available options in database.

In primary study selection criteria, we make sure that published papers that were associated to web service testing techniques were included in search goal.

The search study is being prolonged instead of imperfect using the option (OR) web service AND testing, meaning that we submitted this search string in seven scientific databases which available in Table III.

According to the provided enough information and after limited the selected study to the title, abstract, keyword to make sure, whether the results of the search string are appropriate in the context of the study or not.

By performing the search string in segment 1 of IEEE, a total 674 studies are found between 2010 and 2019. In segment 2 , the study was reduced to 191 when title based execution criteria were applied. In segment 3 , it is limited to 79 after eliminating the duplicate studies especially after reading the abstract. In segment 4 , a total of 20 primary studies were selected after revising full text. Fig. 1 explains the procedure of selecting primary study criteria. The identifying primary studies are available in Table IV. The selection of primary study and review protocol has been well explained in this segment.

Fig. 1 presents the results of steps which provide details of the selection of selected primary study. After exploring the studies, 20 primary studies were selected spanning from 2010 to 2019 from conference, journals and book chapters.

Effective primary studies and 20 potential have been selected by relating the automatic and manual search method. These selected studies are associated directly with the question and interrogations related to answering the questions posed by our study. Selected study introduced technical papers, including SLR's which explored the role and testing approaches in web service in the past few years.

TABLE. II. DATABASE ON-Line SOURCES

\begin{tabular}{|c|c|}
\hline Library source & URL to access \\
\hline Science Direct & http://www.sciencedirect.com \\
\hline ACM Library & http://www.acm.org \\
\hline IEEE Xplore & http://www.ieeexplore.ieee.org \\
\hline ISI Web of Science & http://www.webofknowledge.com \\
\hline Springer Link & http://www.springerlink.com \\
\hline Scopus & http://www.scopus.com \\
\hline Wiley & http://www.onlinelibrary.wiley.com \\
\hline
\end{tabular}

TABLE. III. SEARCh StRIngs, Data Sources AND SELECTED Studies

\begin{tabular}{|l|l|l|}
\hline Name & Results & Query String \\
\hline ACM Library & 34 & $\begin{array}{l}\text { Issues OR Challenges in web service } \\
\text { testing }\end{array}$ \\
\hline Web of Science & 147 & $\begin{array}{l}\text { Issues in web service testing OR } \\
\text { Quality assurance OR attributes OR } \\
\text { issues in web service AND challenges } \\
\text { in web service testing }\end{array}$ \\
\hline Springer Link & 29 & $\begin{array}{l}\text { Issues in web service testing OR } \\
\text { Quality assurance OR attributes OR } \\
\text { issues in web service AND challenges } \\
\text { in web service testing }\end{array}$ \\
\hline Science Direct & 117 & $\begin{array}{l}\text { Testing issues in web service OR } \\
\text { quality assurance OR attributes OR } \\
\text { issues AND testing of Web service }\end{array}$ \\
\hline Wiley & 114 & $\begin{array}{l}\text { Testing Issues in Web Service AND } \\
\text { micro service OR Challenges in Web } \\
\text { Service Testing Issues OR API Testing } \\
\text { Issues }\end{array}$ \\
\hline Scopus & 674 & $\begin{array}{l}\text { Web Service Testing Issues OR } \\
\text { Challenges in micro service Testing }\end{array}$ \\
\hline TOTAL & 139 & $\begin{array}{l}\text { Issues in Web Service Testing OR API } \\
\text { Service Testing Issues }\end{array}$ \\
\hline
\end{tabular}




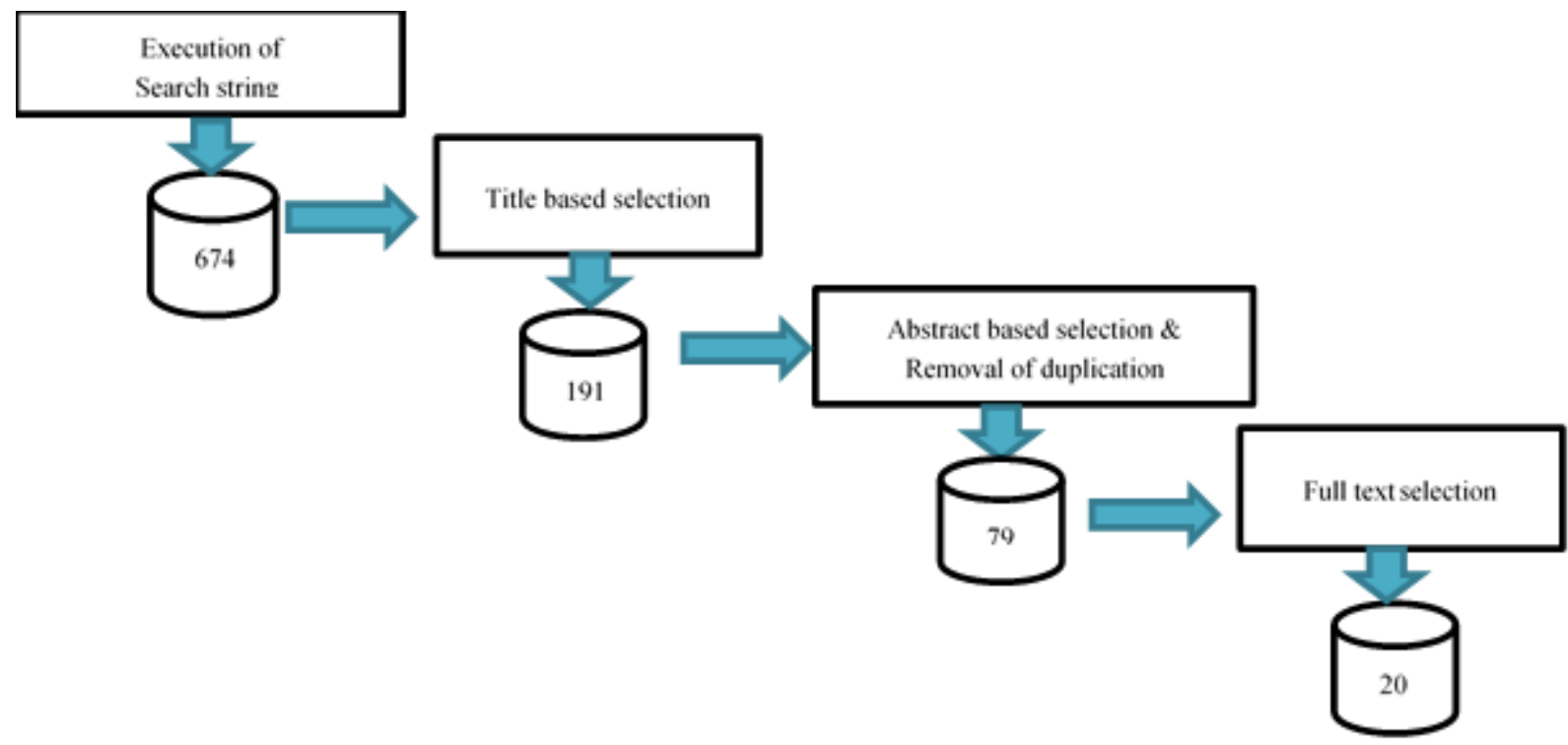

Fig. 1. Phase of Collection Method.

TABLE. IV. The SELECTED PRIMARy Studies

\begin{tabular}{|l|l|l|}
\hline $\begin{array}{l}\text { Study } \\
\text { ID }\end{array}$ & References & Description \\
\hline S1 & {$[38]$} & Specifications for Web Services testing \\
\hline S2 & {$[6]$} & $\begin{array}{l}\text { Performance inquisition of web services using soap } \\
\text { UI and JMeter }\end{array}$ \\
\hline S3 & {$[13]$} & Web Service testing Challenges and Approaches \\
\hline S4 & {$[22]$} & Testing Approaches for SOA and Web Service \\
\hline S5 & {$[29]$} & Semantic Web Services testing \\
\hline S6 & {$[46]$} & $\begin{array}{l}\text { Regression Test Selection for Large-Scale Web } \\
\text { Service Testing }\end{array}$ \\
\hline S7 & {$[47]$} & Functional testing of semantic web services \\
\hline S8 & {$[48]$} & Testing web service \\
\hline S9 & {$[17]$} & A Model-Based Framework for Cloud API Testing \\
\hline S10 & {$[20]$} & $\begin{array}{l}\text { Black-Box Model-Based Regression Testing of } \\
\text { Fail-Safe Behaviour in Web Applications }\end{array}$ \\
\hline S11 & {$[9]$} & $\begin{array}{l}\text { An extensible tool for interoperability testing of } \\
\text { web services }\end{array}$ \\
\hline S12 & {$[42]$} & $\begin{array}{l}\text { A Reusable Automated Acceptance Testing } \\
\text { Architecture for micro services }\end{array}$ \\
\hline S13 & {$[49]$} & Whitening SOA testing via event exposure \\
\hline S14 & {$[10]$} & $\begin{array}{l}\text { A framework to test advanced web services } \\
\text { transactions }\end{array}$ \\
\hline S15 & {$[50]$} & Vulnerability testing tools for web services \\
\hline S16 & {$[3]$} & Performance Analysis of Web Service Composition \\
\hline S17 & {$[5]$} & Performance Inquisition of Web Services \\
\hline S18 & {$[8]$} & $\begin{array}{l}\text { An Abstract Transaction Model for Testing the Web } \\
\text { Services Transactions }\end{array}$ \\
\hline S19 & {$[51]$} & $\begin{array}{l}\text { Web Services Composition Testing Based on } \\
\text { Extended Finite State Machine and UML Model }\end{array}$ \\
\hline S20 & {$[52]$} & $\begin{array}{l}\text { Gremlin: Systematic Resilience Testing of } \\
\text { Microservices }\end{array}$ \\
\hline
\end{tabular}

In Table IV is shown primary studies papers published from 2010 to 2019, which provides an outline of state of the art and categorization of some testing techniques.

The other challenge was to sort from selected testing approaches those related to associated study and which are appropriate to designing primary study conditions. In order to follow the above four segments, 20 most recently published and miscellaneous research papers are listed in Table IV. Furthermore, based on our quality parameter questions from selected primary studied and research exploration method, an analysis of each one has been performed individually.

\section{E. Synthesis and Data Extraction}

In order to extract appropriate material from selected primary study data, extraction have been performed to explain research questions on which research is based. To get the expected outcome, recommendations for such studies are to explore the introduction and methodology. Following is the required separated material from all selected primary studies:

- The source of selected primary studies, i.e. from conference, the title or journal.

- The structure of each study conducted.

- Method pros and cons of web services of both SOAP and RESTful testing technique.

- Supportive facts of web service testing approaches.

- Provision of tools for a web service testing technique.

- Necessary adoptive facts for web service testing techniques.

- The facts required to respond to the selected primary study questions.

The summary of data extractions is shown in Result and Discussion segment to explain their importance in terms of appropriate research. Furthermore, the explanation to classify the selected primary and other studies were incorporated and 
the categorization and execution process and its flow are well described as shown in Fig. 2. Narrative synthesis was used to elaborate the research methodology performed to get selected primary studies for analysis in Table IV.

This section explains the review protocol and procedure selected for the primary study. To evaluate and understand the specific area or study of interest, literature review is an efficient way to find the questions of respective research [53]. This procedure validates that the current research is reasonable. Consistent with recommendation mentioned by Kitchenham in Fig. 2, the literature review has three significant segments, which are planning, conducting and documenting. Requirement of the study is already mentioned in Section 1, and the description of research questions are also available in Table I. Data extraction procedures are explained in Fig 1. The outcome of selected primary study is given in Fig. 1 as well.

All research questions are appropriate to test and to quality the web service that is being explored through current approaches. Additionally, this study includes some parameters that are most common and important from selected primary studies for quality assurance.

In Fig. 2 is shown the description of a categorization pattern and extraction of data, including all phases of the producer which has been executed for selected primary study.

The classification of the selected primary study by year is shown in Fig. 3. The most published papers that have been produced and the abstract web service testing techniques research study were in 2018.
Fig. 3 presents the classifications of the major contribution by year. It shows that most papers were published for web services testing approaches in 2018. Similarly, Fig. 3 explains that there is a big discrepancy between the published papers from 2010 to 2019 regarding web service testing techniques or methodologies and tool supported techniques.

This study presents the analysis of the following parameters to answer all four research questions having one goal, which is how to achieve and progress the quality of web services testing for both SOAP and RESTful testing. Selected parameters that come through from primary study using search strings include security, performance, interoperability, maintainability, reusability, reliability and efficiency. The actual goal is also to make a thorough evaluation of most common issues while testing these parameters found in a selected primary.

To achieve these goals, according to RQ1, RQ2 and RQ3, we introduced a sequence of research questions as shown in Table I. We specified four research questions to analyse the primary study. The most common issues were raised while performed testing for selected parameters using existing techniques against web service testing and its type SOAP and RESTful and an explanation of these common issues and parameters is presented in Fig. 4.

RQ1 and RQ2 further elaborate the need for selected common issues with quality related aspects and concerns with respect to testing of web services. Parameters are divided intotwo categories, SLR's and Journal, symposium, chapters. Most of the research of primary study includes these classifications according to common parameters using existing techniques, models, framework and approaches.
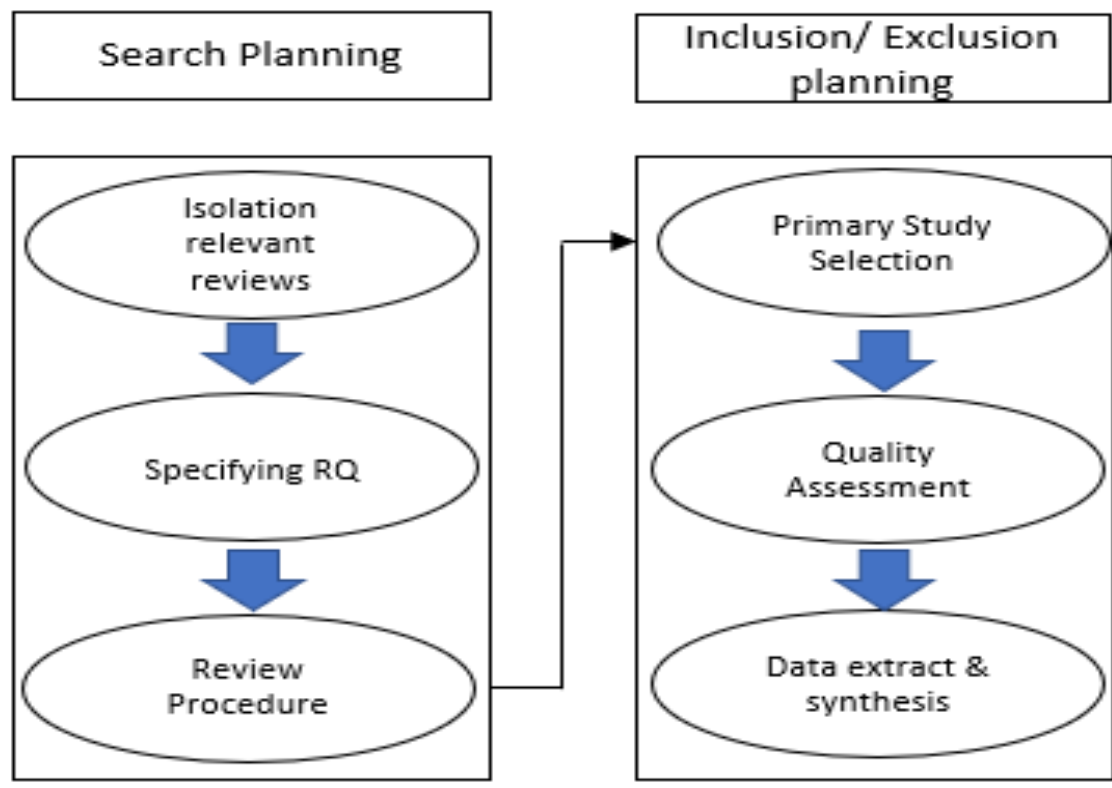

Evaluation of Results
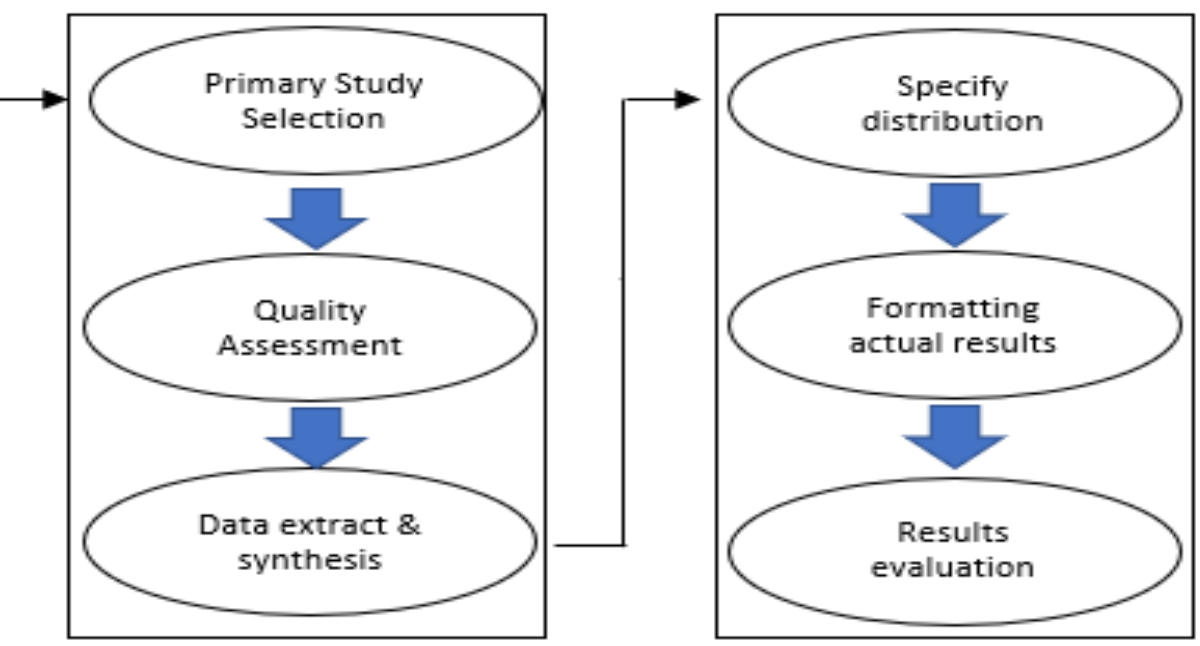

Fig. 2. Research Methodology from [45]. 


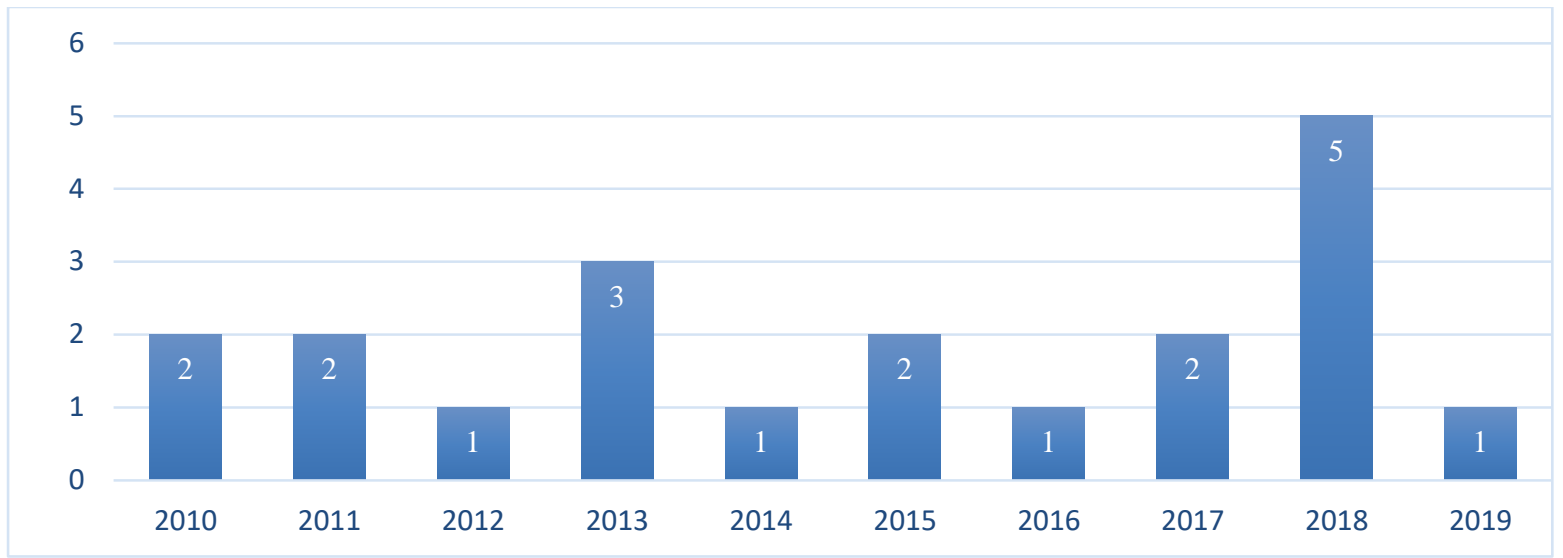

Fig. 3. Primary Study Year Wise Trend.

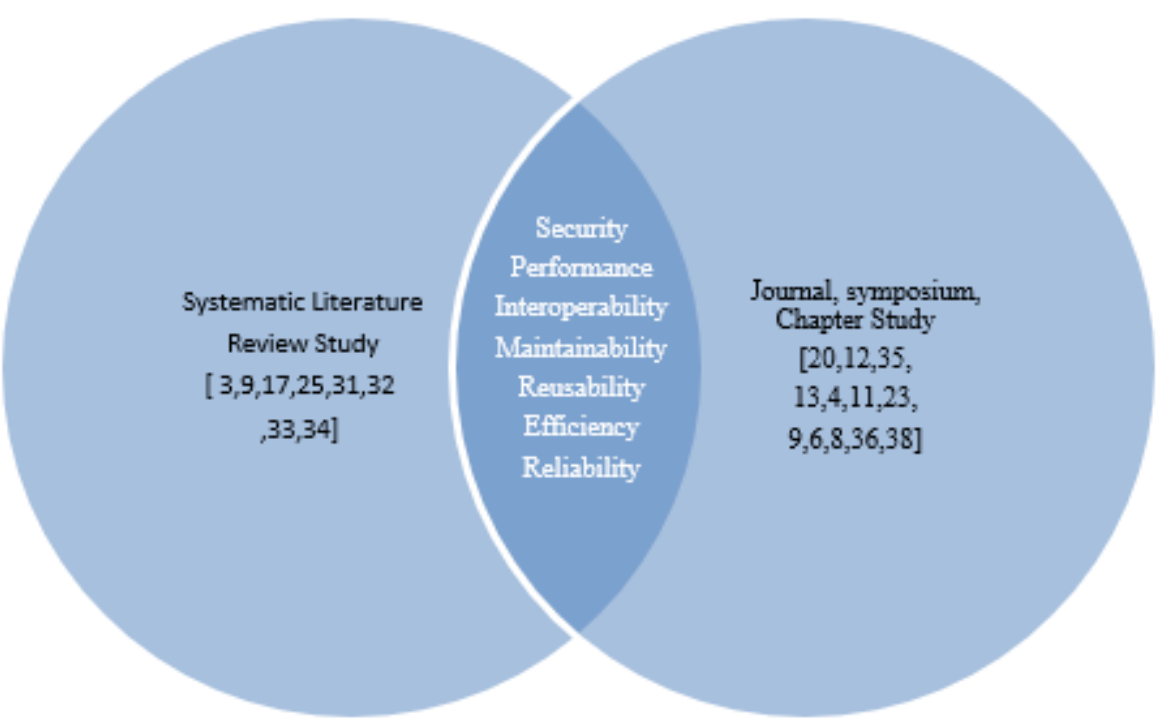

Fig. 4. Web Service Testing Issues in Common Parameters.

\section{1) RQ1"What are the issues web service testing?"}

The following explanation provides the details of each quality attribute which the most common issues are found in selected primary study from Table IV.

a) Security is a basic term in software and web service testing in the context of software or web service testing to play out its errand by using a base measure of resources while successfully communicates either within the system or other systems. Most of the time, in order to exchange data and information, a system must interact with other systems using different mechanism. For web service security testing [54, 55], this is a critical element, as the mechanism or tool should have the ability to make sure the security interrelate and then manage with remaining components.

b) Performance specifies the ability of the mechanism to ensure performance quality and also is a measure of how fast a request of service can be completed. Performance also ensures testing [5] the sensitivity under the specific workload and stress situations. There are two important types of performance testing which are stress and load testing. Stress testing is usually conducted to test the performance of a system under extreme capacity, increasing its maximum load. Load testing is performed by executing the system under explicit predefined load capacity to realise its performance and efficiency.

c) Interoperability refers to the ability of the system to interrelate efficiently with different frameworks whenever needed [9]. It also refers to making sure while testing that web services and system are interoperable to implement services between the different development environments. Usually a framework is needed to perform data trade through different components to associate with additional frameworks. This is a vital element, as the instrument should have the capacity to collaborate and arrange with outer parts.

d) Maintainability This attribute assesses if the code of the system can be retained to address weaknesses, alter or develop in the upcoming changes in the system. Code practicality sense can be sophisticated by following high coding standard, doing proper documentation of code and keeping up consistency to the extent programming dialect and coding benchmarks [56]. From future perspective code 
modularization and Object-Oriented Programming can likewise help in code.

e) Reusability This term specifies the ability of the testing mechanism to accomplish reusability of web software and web service testing. Under explicit embedded the same functionality and circumstances, in this study reusability deals with sensitivity of the web service testing [42]. Multiple fluctuating constraints can be reused from the earlier version's test cases of web service. So, testing of reusability can reduce work effort to provide solution with constraint standards for those variables while testing the latest changes in the system and application.

f) Efficiency This attribute shows the capacity of web service and software system to play out and run by using a base measure of assets. Efficiency in software and web service testing will assess if the web service testing makes the most efficient consumption of framework assets like processor parameter, RAM, transfer speed and so forth. An instrument consuming excessive plate space or memory shows a low proficiency [57]. Thus, the testing model, framework or technique which is being used must sure prompt results while performing efficiently as a testing technique that does not respond in time to produce the expected results can be considered as inefficient.

g) Reliability this parameter represents the ability of the application to execute the given assignment by consuming a lowest volume of assets, which signifies the capacity of a web service testing to execute the given necessary tasks under mentioned circumstances within the respective time period. The purpose of the reliability [58] is to make sure the overall measures of web service testing and its quality are maintained. Reliability will evaluate the usage of system resources like RAM, processor capacity, bandwidth while testing web service in this study.

The mentioned testing features and terms are the direct and valuable testing opinions, and must thus be valued and realised for web service quality testing.

2) RQ2 What are the quality related aspects and concerns with respect to testing of web services?

Fig. 5 is concerns the analysis of selected studies to demonstrate the RQ2 quality related aspects, which are security, performance, interoperability, maintainability, reusability, efficiency, reliability with respect to RQ1 as shown in Fig. 4. When dealing with web services testing, additional significance is given to applied research leading to resolutions than to theoretical exploration like literature reviews. Due to the large number of web service testing approaches, research studies that relate to the experiments applied in the lab and are not yet used in an actual industry environment. Based on implemented experiments, it can be concluded that this study has many open exploration problems that require further investigation.

There seems to be an overflow in web service testing to address common quality related aspects as shown in Fig. 4.
This is because multiple testing techniques that might be reasonably comparable to the comprehensive level are stated with different titles. This could be a result of freshness of study testing area because of deficiency of recognised terms. Identifying approaches that follow related techniques are not credible with particular information mentioned in the abstract as well as introduction and conclusion level. This is one of the prominent explanations that inspire us to extend this study to a systematic literature review.

3) $R Q 3$ What are the existing solutions to solve the web service testing issues?

It is useful for researchers to recognise latest solution capacities that have not as yet been explored comprehensively. This requires a focus on the limitations, disadvantages and gaps of the current testing techniques. However, the answer to RQ3 well be explained in following Result and Discussion section.

The outcome in testing of web service is providing a comprehensive overview of the current state of the research from this mapping study. The purpose of this study is to produce a thorough taxonomy of web services testing techniques in the context of selected parameters from primary study.

Existing testing technique and proposed solution in this study is done through different methodologies which are frameworks, models and tools available in Table VII. Other testing strategies, which are regression testing and load testing, security testing has been obtained from these existing techniques. The RQ3 question is useful for the testers to select testing techniques before providing service. To answer this question, our attention will be on parameters and testing techniques utilized in each study.

\section{4) RQ4 How were existing testing techniques applied?}

Test generation process and techniques focus on the procedure which served to produce the web service auto test proposed to ensure the quality of test selection methods. By applying the manual test, auto test, graph search algorithms, model-checking, reasoning and other manual test is the process to ensure web service testing. This is done to place greater emphasis on the major contribution for each selected analysis mentioned.

According to the earlier mentioned parameters, there is a need to explain how existing approaches and techniques are applied to meet the requirements of RQ4. In this review authors suggested some models, tools and techniques to produce product to end user. Therefore [43, 59] introduce new approaches for testing web service. Author in [25] presents a black box testing technique to improve the quality. A research conducted by [3] introduced performance testing approach, which tests and assesses the general behaviour or efficiency of the structure of the system under business hours and several solutions have been proposed in primary study by the authors. 


\section{Selected Study Parameters}

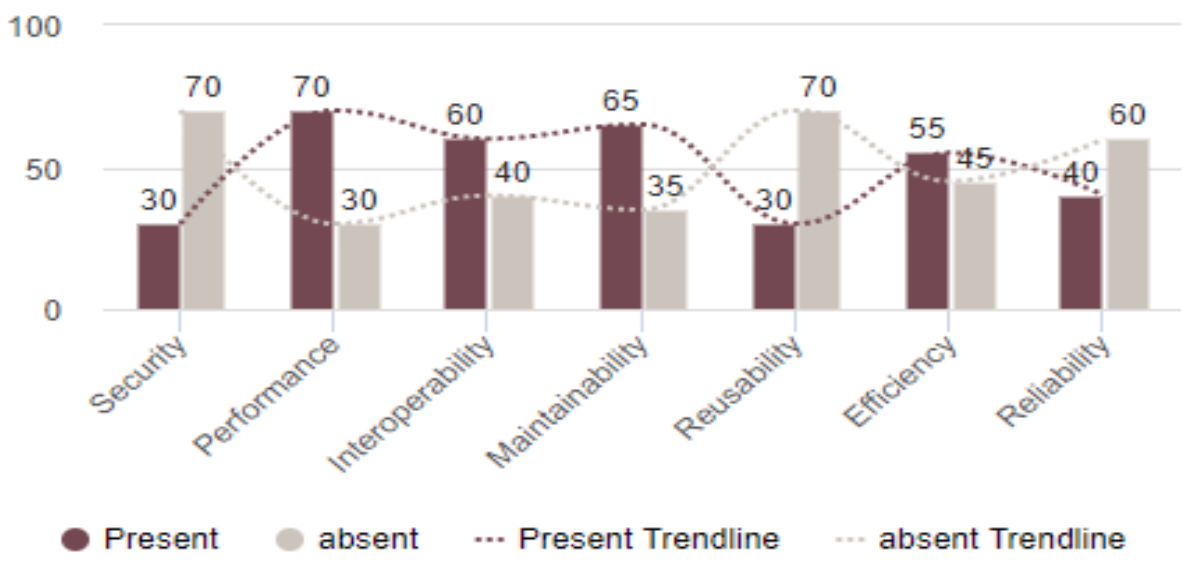

Fig. 5. Results and Findings of Evaluating Studies.

\section{RESULT AND DISCUSSION}

\section{A. Web Service Quality and Analysis}

To formulate the results to address research questions for web service testing techniques with a solution, Quality parameter outcomes have been introduced in Table V. The signs " $\checkmark$ " and "x" have been introduced for present and absent, respectively, to display parameters that the explicit approaches represent.

For web services quality assurance, the testing mechanism for security, performance, interoperability, maintainability, reusability, efficiency, reliability have been analysed in detail.

This segment discusses the results of the study mentioned in Table V. Collectively, each subcategory attempts to provide appropriate answers to the questions we have defined in Table I. It also explains the implementation of web services testing and how these techniques are introduced by using different methods to implement these approaches, model and frameworks.

From Table $\mathrm{V}$ it is known that almost $70 \%$ of testing approaches claim to be appropriate for security, performance, reusability and more than $60 \%$ interoperability, maintainability and reliability and reusability efficiency of web service testing. It is significant for the web service to work in an orderly manner for appropriate functioning of web services and its testing as it has the competency of effective incorporation and procedure for performance, interoperability, maintainability, reusability and reliability. These parameters show the value of being effective and some of the technique provides solutions for efficiency. Most of the studies do not discuss efficiency in their experiments using different testing techniques as shown in Fig. 5. More than 55\% of testing approaches are focused to ensure the efficiency of testing in web service.

This study proposed and presents the testing approaches as well as code maintainability, security, efficiency, reusability, reliability, interoperability, performance, which are important to ensure the quality of web service testing for both SOAP and RESTful. Proposed techniques consider interoperability, which is crucial for web service testing. Interoperability and security are vital elements to ensure the quality of the system during testing, but most studies do not consider and discuss it as per analysis in Fig. 5. The same is true for reliability and reusability while testing web service where even $40 \%$ techniques are not followed to ensure better quality testing. It is essential to make sure that all functional and non-functional desires are satisfied, whether these requirements are predefined are or not while web services testing.

The major contribution of results are shown Table VI, where the leading role to ensure the quality of web services testing is performed using maintaining security, interoperability, maintainability, reusability, efficiency, reliability parameters using different techniques, tools, framework or models. To test the mentioned parameters according to the selected primary studies, Table VI uses research methodology as shown in Fig. 2.

Table VI presents the major classifications in this area according to RQ3 and RQ4 resolutions using frameworks, tools and existing approaches as a result of growth in the web service testing production and fluctuation in the performance of business. The speed of testing procedure has increased according to the primary studies based on web service testing structures and influence listed in percentage in Fig. 6.

The classification of the study includes framework, model or tool support in Fig. 6. It can be seen that $70 \%$ of the works are supported by different techniques or methods, with $20 \%$ of the works proposing tools which developed for web service testing purpose and $40 \%$ of studies introducing different frameworks models suggested by the authors.

In order to find keywords and planning that improve the outcome, in this paper is selected conditions distinguished by reading the abstracts of the papers. The designated keywords and ideas are taken from related available research to present a categorization of structure that replicates an awareness of the base of the research study input. In this manner, we have classified the papers into categories (called Major Contribution) mentioned in categorization pattern in Fig. 6. This procedure was completed using spreadsheets for each facet and its scopes. 
TABLE. V. SELECTED PRIMARY STUDIES FOR ANALYSIS

\begin{tabular}{|c|c|c|c|c|c|c|c|c|c|c|c|c|c|c|c|c|c|c|c|c|}
\hline Parameters & స్త్ర & ्ָّ & $\Xi$ & $\sigma$ & $\Xi$ & 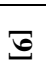 & $\bar{\Xi}$ & $\Xi$ & $\Xi$ & $\widetilde{\infty}$ & $\stackrel{N}{\Xi}$ & $\underline{\mathbb{N}}$ & $\underset{\Perp}{\rightleftarrows}$ & $\bar{U}$ & 岕 & $\stackrel{\widetilde{J}}{J}$ & $\underset{\mathbb{N}}{\mathbb{N}}$ & $E$ & $\Xi$ & $\underset{\mathscr{\varpi}}{\mathscr{\varpi}}$ \\
\hline Security & $\mathrm{x}$ & $\checkmark$ & $\checkmark$ & $\mathrm{x}$ & $\mathrm{x}$ & $\mathrm{x}$ & $\checkmark$ & $\mathrm{x}$ & $\checkmark$ & $\checkmark$ & $\mathrm{x}$ & $\mathrm{x}$ & $\checkmark$ & $\checkmark$ & $\mathrm{x}$ & $\checkmark$ & $\mathrm{x}$ & $\mathrm{x}$ & $\mathrm{x}$ & $\mathrm{x}$ \\
\hline Performance & $\mathrm{x}$ & $\checkmark$ & $\checkmark$ & $\checkmark$ & $\checkmark$ & $\mathrm{x}$ & $\mathrm{x}$ & $\checkmark$ & $\checkmark$ & $\checkmark$ & $\mathrm{x}$ & $\mathrm{x}$ & $\mathrm{x}$ & $\mathrm{x}$ & $\mathrm{x}$ & $\checkmark$ & $\mathrm{x}$ & $\mathrm{x}$ & $\checkmark$ & $\checkmark$ \\
\hline Interoperability & $\mathrm{x}$ & $\mathrm{x}$ & $\mathrm{x}$ & $\mathrm{x}$ & $\mathrm{x}$ & $\mathrm{x}$ & $\checkmark$ & $\mathrm{x}$ & $\checkmark$ & $\checkmark$ & $\mathrm{x}$ & $\mathrm{x}$ & $\checkmark$ & $\mathrm{x}$ & $\checkmark$ & $\checkmark$ & $\mathrm{x}$ & $\mathrm{x}$ & $\mathrm{x}$ & $\mathrm{x}$ \\
\hline Maintainability & $\mathrm{x}$ & $\checkmark$ & $\mathrm{x}$ & $\mathrm{x}$ & $\checkmark$ & $\mathrm{x}$ & $\mathrm{x}$ & $\mathrm{x}$ & $\mathrm{x}$ & $\checkmark$ & $\mathrm{x}$ & $\mathrm{x}$ & $\mathrm{x}$ & $\mathrm{x}$ & $\mathrm{x}$ & $\checkmark$ & $\checkmark$ & $\mathrm{x}$ & $\mathrm{x}$ & $\checkmark$ \\
\hline Reusability & $\mathrm{x}$ & $\mathrm{x}$ & $\mathrm{x}$ & $\checkmark$ & $\mathrm{x}$ & $\mathrm{x}$ & $\mathrm{x}$ & $\mathrm{x}$ & $\mathrm{x}$ & $\mathrm{x}$ & $\checkmark$ & $\mathrm{x}$ & $\mathrm{x}$ & $\mathrm{x}$ & $\mathrm{x}$ & $\mathrm{x}$ & $\checkmark$ & $\mathrm{x}$ & $\mathrm{x}$ & $\mathrm{x}$ \\
\hline Efficiency & $\mathrm{x}$ & $\mathrm{x}$ & $\mathrm{x}$ & $\mathrm{x}$ & $\mathrm{x}$ & $\checkmark$ & $\mathrm{x}$ & $\checkmark$ & $\checkmark$ & $\mathrm{x}$ & $\checkmark$ & $\checkmark$ & $\mathrm{x}$ & $\checkmark$ & $\mathrm{x}$ & $\mathrm{x}$ & $\mathrm{x}$ & $\checkmark$ & $\checkmark$ & $\checkmark$ \\
\hline Reliability & $\checkmark$ & $\mathrm{x}$ & $\mathrm{x}$ & $\mathrm{x}$ & $\mathrm{x}$ & $\checkmark$ & $\mathrm{x}$ & $\checkmark$ & $\checkmark$ & $\checkmark$ & $\checkmark$ & $\checkmark$ & $\mathrm{x}$ & $\mathrm{x}$ & $\checkmark$ & $\mathrm{x}$ & $\mathrm{x}$ & $\checkmark$ & $\checkmark$ & $\checkmark$ \\
\hline
\end{tabular}

TABLE. VI. MAJOR CONTRIBUTION IN THE LITERATURE

\begin{tabular}{|l|l|}
\hline Contribution Types & References \\
\hline Technique/Method & {$[4],[29],[6],[14],[22],[34],[35],[36],[37],[32],[40],[41],[38]$} \\
\hline Tool & {$[39],[10]$,} \\
\hline Framework/Model & {$[21],[18],[40],[9],[7],[11]$} \\
\hline
\end{tabular}

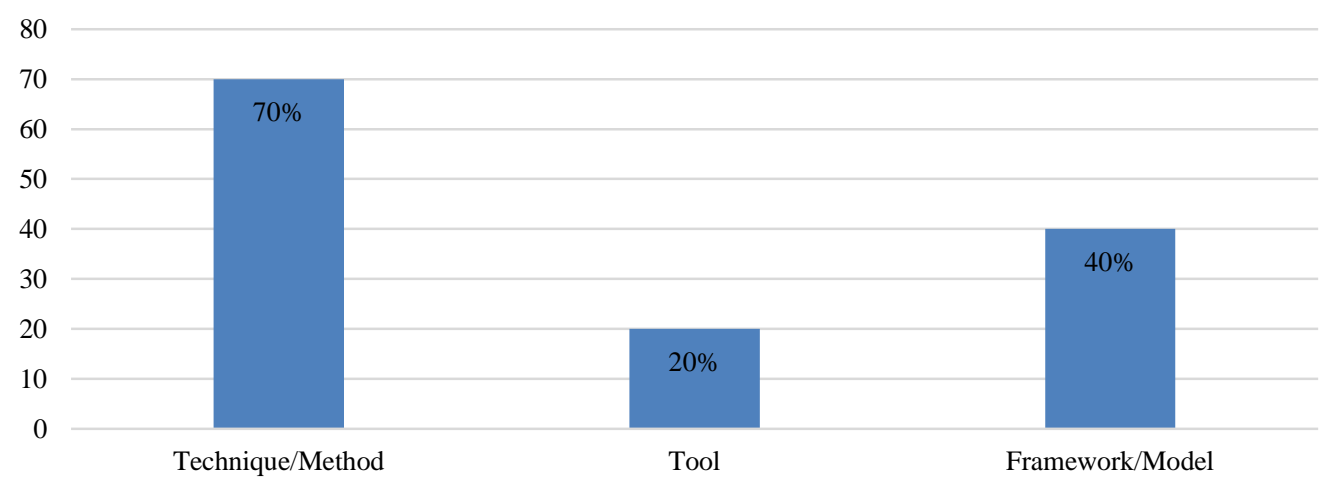

Fig. 6. Classification of the Major Contribution.

The classification of selected primary study that has SOAP and RESTful web service type support are presented in Fig. 7, which shows a sample illustration of the types of existing web service. As mentioned earlier, basically, there are two types of web services, SOAP and REST. However, SOAP is further classified into Remote Procedure Call (RPC) style and Document XML style.

It is shown that almost $70 \%$ of the studies supported SOAP while 30\% explained for Restful. The authors use Remote Procedure Call (RPC) style and Document XML style because Document XML style is more effective, efficient and reusable while performing testing, specifically for interoperability, performance, security and maintainability shown in Table $\mathrm{V}$ using different techniques or methods presented in Fig. 8.

In order to use discussed prototypes, Fig. 8 shows the distribution of the major contribution over the web service types. Note that the analysis only contributes selected primary study available in Table IV. We can identify the dissimilarity between the quantity of SOAP and RESTful studies in supported studies as SOAP is makes it much easier to communicate between the interfaces and is easy for developers to deploy.

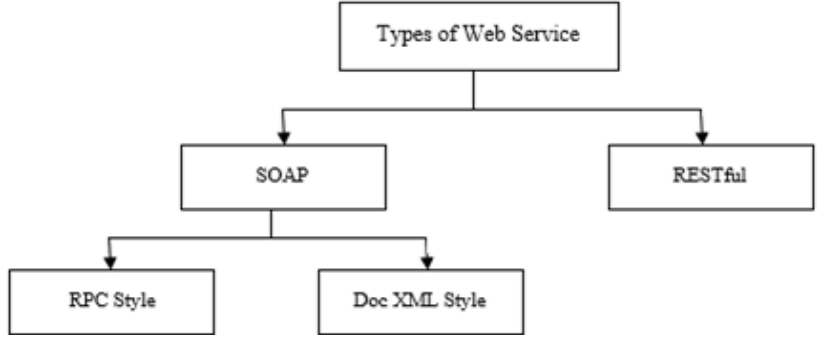

Fig. 7. Types of Web Service.

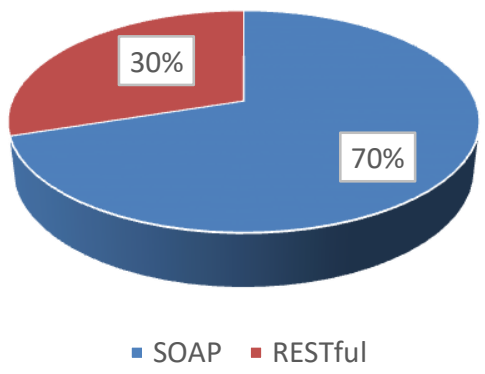

Fig. 8. Major Contribution of Web Service Types. 
TABLE. VII. CONTRIBUtion OF WEB SERVICE TyPeS FOR ANALYSIS

\begin{tabular}{|c|c|c|c|c|c|c|c|c|c|c|c|c|c|c|c|c|c|c|c|c|}
\hline $\begin{array}{l}\text { Web Service } \\
\text { Types }\end{array}$ & స్త & $\underline{\widetilde{\sigma}}$ & $E$ & $\sigma$ & $\Xi$ & $\sigma$ & $\bar{\sigma}$ & $\Xi$ & $\Xi$ & $\varpi$ & $\stackrel{N}{\Xi}$ & $\stackrel{N}{N}$ & $\underset{ \pm}{\overline{ \pm}}$ & $\underset{\tilde{u}}{\tilde{u}}$ & $\bar{\sigma}$ & $\stackrel{\widetilde{J}}{J}$ & $\stackrel{\underset{\sim}{\sim}}{\widetilde{U}}$ & E & $\Xi$ & $\underset{\mathscr{\omega}}{\breve{\omega}}$ \\
\hline SOAP & $\checkmark$ & $\checkmark$ & $\checkmark$ & $\checkmark$ & $\checkmark$ & $\mathrm{x}$ & $\checkmark$ & $\checkmark$ & $\checkmark$ & $\checkmark$ & $\checkmark$ & $\checkmark$ & $\checkmark$ & $\mathrm{x}$ & $\checkmark$ & $\checkmark$ & $\checkmark$ & $\checkmark$ & $\checkmark$ & $\mathrm{x}$ \\
\hline Restful & $\mathrm{x}$ & $\mathrm{x}$ & $\checkmark$ & $\mathrm{x}$ & $\checkmark$ & $\checkmark$ & $\mathrm{x}$ & $\checkmark$ & $\mathrm{x}$ & $\mathrm{x}$ & $\checkmark$ & $\mathrm{x}$ & $\mathrm{x}$ & $\checkmark$ & $\checkmark$ & $\mathrm{x}$ & $\mathrm{x}$ & $\mathrm{x}$ & $\mathrm{x}$ & $\checkmark$ \\
\hline
\end{tabular}

TABLE. VIII. Major Contribution of Web Service Types in Selected Parameters for ANalysis

\begin{tabular}{|c|c|c|c|c|c|c|c|}
\hline $\begin{array}{l}\text { Web } \\
\text { Service } \\
\text { Types }\end{array}$ & 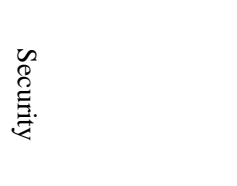 & 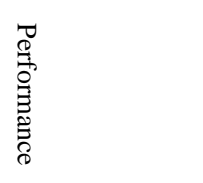 & 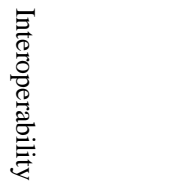 & 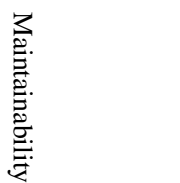 & 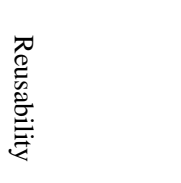 & 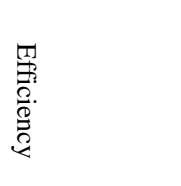 & 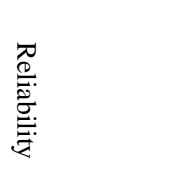 \\
\hline SOAP & $\begin{array}{l}{[29],[39],[4],[14],} \\
{[18],[21][35],[37]}\end{array}$ & $\begin{array}{l}{[39],[4],[6],[14],} \\
{[21],[34],[35],} \\
{[37]}\end{array}$ & $\begin{array}{l}{[29],[39],[10],} \\
{[18],[36],} \\
{[37]}\end{array}$ & $\begin{array}{l}{[39],[10],[11],} \\
{[21],[34],}\end{array}$ & $\begin{array}{l}{[29],[35],[35],} \\
{[32],[41],} \\
{[41]}\end{array}$ & $\begin{array}{l}{[11],[37],} \\
{[40],[41],[38]}\end{array}$ & $\begin{array}{l}{[29],[6],[9],} \\
{[14],[34],[35]} \\
{[37],[40],[38]}\end{array}$ \\
\hline RESTful & $\begin{array}{l}{[4],[18],[21],} \\
{[35]}\end{array}$ & {$[4],[18],[21]$} & {$[18],[36]$} & {$[11],[21]$,} & [32] & {$[11],[38]$} & [9],[32],[38] \\
\hline
\end{tabular}

By using primary study available in Table IV we have performed analysis against each study of web service type that has been formulated in tabular way as presented in Table VII. The signs " $\checkmark$ " and " $\mathrm{x}$ " have been introduced to indicate the presence and absent of discussed primary study. Here is the major contribution of web service types in Table VII. It presents the main influence for web service types, SOAP and RESTful against selected parameters according to the selected primary studies.

The major contributions are shown in Table VII, which presents the main influence in web service testing for SOAP and RESTful done through maintaining security, interoperability, maintainability, reusability, efficiency, reliability issues using different techniques, tools, framework or models to test the mentioned parameters according to the selected primary studies.

For consistency, the current study explicitly selected parameters presented in Table VIII, which reports what web service type is used against which parameter. The explicit selected parameters presented in Table VIII address the web service types.

\section{B. Challenges of Web Service Testing}

According to the analysis of earlier primary studies, it has been observed that measures to ensure the quality of service must be satisfied according to the RQ1 and RQ2. Additionally, some other system architectural parameters to improve the quality of web service testing are also significant, for example security and efficiency measures. Most of the quality assurance parameters have been discussed in Table VIII to improve testing of web services using different techniques.

There are possible that the one testing approach will be the best in one testing standard and the worst in testing another. But in order to reduce the gap between testers and developer, it is important to improve the quality of the product because ultimately only client is going to use the service irrespective of the product after testing. The other issue, which is a challenging one, is increasing the quantity of APIs, as there are different services against each API [50]. Moreover, continuous maintenance of web service is also problematic to ensure the quality as it is possible that every user may not maintain or upgrade his service. Therefore, it is important to improve and introduce such techniques to ensure better quality better that can work for all kinds of services rather than maintaining quality for the different versions individually. The most significant points are to assure performance, security, interoperability, maintainability, reusability, reliability and efficiency of web services as well as for micro service through testing.

RQ3 is focused to assure better quality in web services. In addition to above, there should be more extensive work required to:

- Introduce the quantity of testing efforts in terms of frequency that should be required to make the quality better.

- Introduce the necessary levels of testing consistent with each perspective (i.e. Provider, Integrator, Developer, and Third Party as well as for End User).

- Possible testing techniques at Integrator and third-party level.

- Few quality features are mentioned in selected studies to improve quality performance for every type of web service or micro services testing which are helpful in finding testing area.

Twenty primary studies are shown in Table IV and we classified them into the four categories of web service testing on the basis of latest techniques, The primary study we have selected includes the use and discussion of black box testing technique in (13 papers), regression testing selection (2 papers), performance testing explained in (4 papers), and white box testing discussed in (1 paper) only, which are discussed in detail in review method section. 
After performing analysis and evaluation to conclude the current state of the art of useful (black box, white box, regression testing and load testing) in a web service in order to isolate the challenges related with these existing techniques, tools and frameworks which introduced in Table IX.

Fig. 9 shows the classification of testing technique and testing level facets according to Table IX. Therefore, it has been observed in the different search studies that $50 \%$ of the primary study discusses and concentrates on black box testing. Similarly, many studies proposed regression testing regarding test case concerns. Only one study is about white box testing and some authors discussed load testing in selected studies as shown in Fig. 9. These selection criteria are selected according to RQ4 from selected primary studies.

Fig. 9 shows the results of testing level used in primary studies and it seems that $50 \%$ of the selected studies propose black box testing while $35 \%$ propose regression testing, $10 \%$ study's authors suggested load testing and 5\% for white box testing in order to ensure the quality of web service testing of security, performance, interoperability, maintainability, reusability, efficiency and reliability. Therefore, the purpose of using these suggested testing techniques from black box methodology can be concluded as:

- Easy to use: It is easy to use as the testing team is not required to understand the internal structure of the system. Therefore, test case generation process is a relatively stress-free work.

- More rapid testing: In this testing, the testers must only interact with system's Graphic User Interface (GUI), no time is exploited in analyzing the structure of the code. This kind of practice saves the lot of time of testers and makes the testing process much easier and faster.

- Simpler process: When the testers must deal with large and composite systems, some techniques or methods like black box testing make the testing process simpler because testers are only concerned with the valid and invalid inputs and the expected output.

The following studies are associated with the relevant SOAP [51], [52] and RESTful testing [50], [20], [53] techniques. The summary of the study stated that explanations of web service testing can be further improved using existing techniques, models, frameworks and tools of testing by supporting the responsibilities that are required for the capability and understanding of a service tester. However, most of the existing web service testing techniques, frameworks, models and tools [46], [10] still need improvement as most suggested approaches are in their early stages. Most of the suggested techniques only provide the results of initial conclusions, which indicates that there is a need for more concentration and need to discuss further improvements in web service testing area, specifically on quality parameters like security [3], performance [4], interoperability [10], maintainability [46], reusability [32], efficiency [38], and reliability [11].

The primary study is focused on functional and nonfunctional web service requirements. It also concluded that it is possible to derive testing from specifications of selected parameters and the challenges of web service testing are, in general, the same as in the testing of traditional web services. Furthermore, it is recommended that instructions for future exploration of the study focus on existing techniques, tools and frameworks to improve web service testing. Transformation techniques relative to research the different works should be initiated to explore new techniques $[15,52,59]$ to identify web service testing techniques. The testing of web service with the selection of the most important parameters assured its quality whenever the specification of web service changed to develop or introduce different techniques, tools, framework, and models to test quality parameters. Still, the majority were not properly validated or evaluated during testing of web service.

\section{Test Method used for Testing Web Service}

This review found a number of known testing techniques completed for web service such as regression testing, model based testing, load testing, rule based testing and performance testing. Built-In Operational Testing, Passive Testing, different test case methods, tools and models introduced in primary study make the web service testing better and improve its quality. [60] Study introduces structural and operational testing technique, which is obviously a white box testing system as it associated with structure of web services programming. [61] Presents regression testing techniques to ensure the latest program or code alteration has not affected current structures.

In [62] authors have presented technique for reporting of test results which is an XML- based technique. As per our investigation, most of the testing approaches are state or model based which are operational for testing of web services.

For web services, there is a requirement of testing from different interpretations with less information on user end. There should be a testing technique which can be applicable for every sized service as the services can be small and large. Therefore, different testing techniques, tools and models are more appropriate to use because of time effective technique and ease of use. The following figure presents the same idea to cater selected parameters using existing testing techniques from selected primary study.

Fig. 10 shows the combination between selected study parameters, testing techniques and testing level facets. However, we have to ensure good quality testing techniques which have been introduced in recent years and also included primary selected studies. Below is the comparison to ensure that selected study tools or framework offer good quality testing techniques.

TABLE. IX. Major Contribution of Testing Techniques in Web SERVICE

\begin{tabular}{|l|l|}
\hline Testing Types/levels & References \\
\hline Black Box & $\begin{array}{l}{[29],[21],[22],[34],[35],[36],[37],[18],[10],[32],[11]} \\
{[39],[9]}\end{array}$ \\
\hline Regression Testing & {$[29],[14],[40]$} \\
\hline Performance Testing & {$[7],[4],[6],[41]$,} \\
\hline White Box & {$[38]$} \\
\hline
\end{tabular}




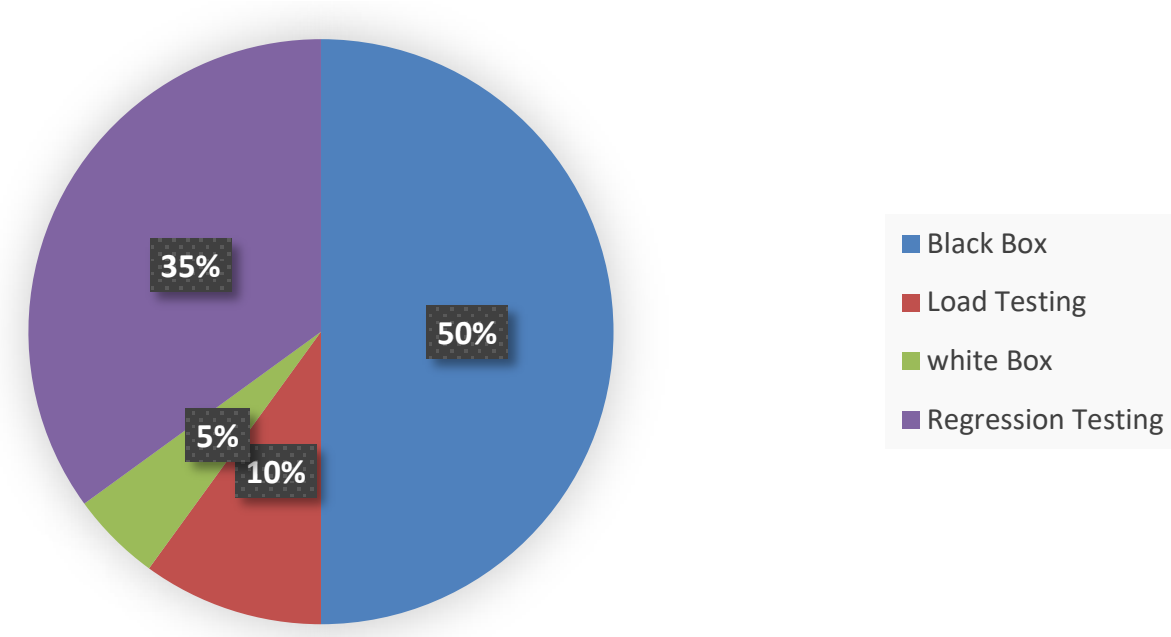

Fig. 9. Contribution of Solution Techniques with Respect to Existing Studies

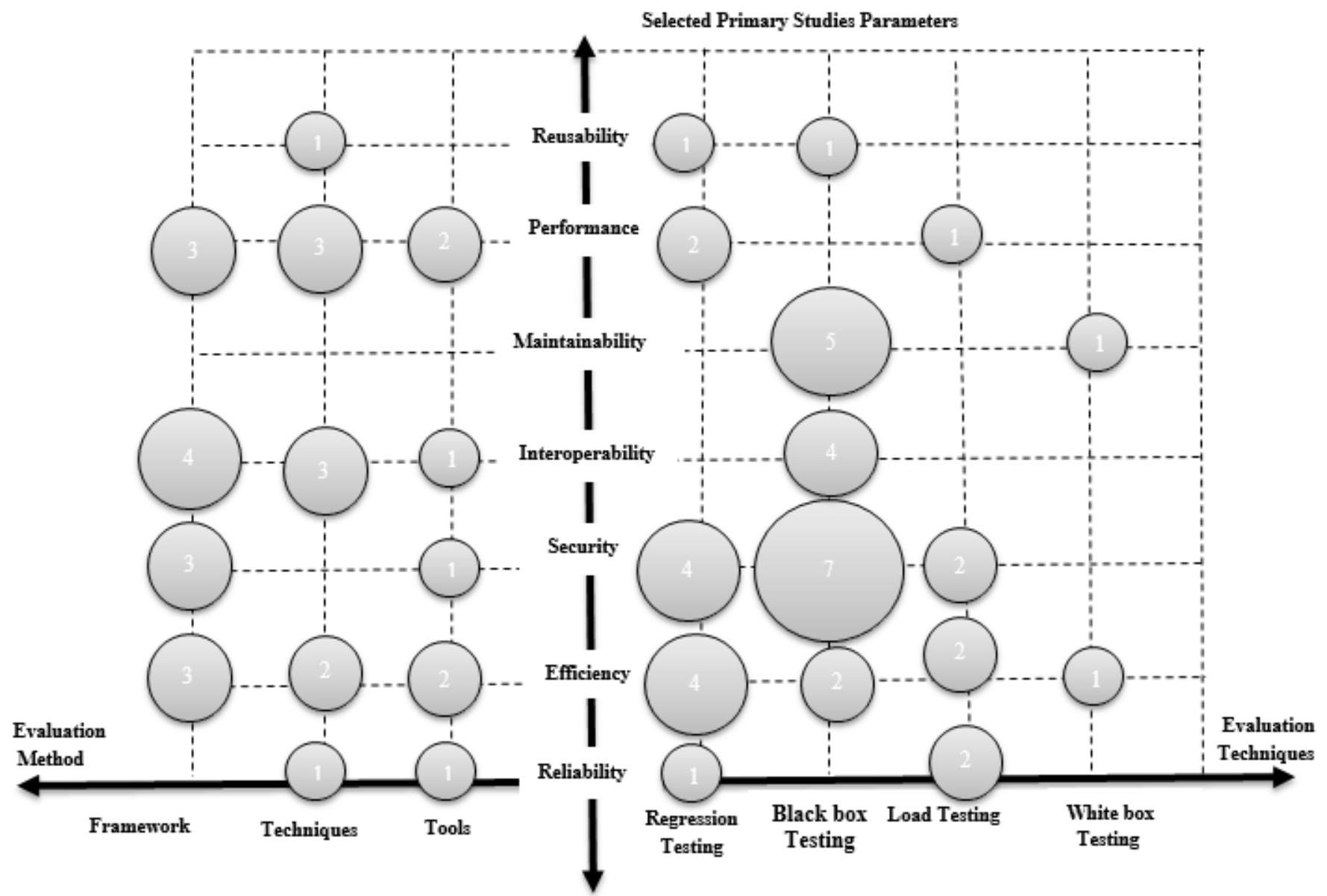

Fig. 10. The Relationship between Primary Study, Testing Techniques and Testing.

The symbols " $\checkmark "$ and "x" are used, respectively, for presence or absence from the selected primary study. The major contribution of web service quality testing attributes are shown in Table X, which indicates the main influence for quality studies of web service testing techniques according to the selected primary studies. Table X shows quality attributes that we have defined in our study for good and valuable quality testing techniques. When we discuss quality attributes of web service testing, we are basically analysing what has been claimed in the primary study, the study method used and how the research question was answered using defined quality parameters. 
TABLE. X. MAJOR COMPARISON OF QUALITY STUdIES

\begin{tabular}{|c|c|c|c|c|c|c|c|}
\hline $\begin{array}{l}\text { Selected Primary } \\
\text { Study }\end{array}$ & $\begin{array}{l}\text { Comprehensive } \\
\text { literature review }\end{array}$ & $\begin{array}{l}\text { Proposed } \\
\text { Techniques }\end{array}$ & $\begin{array}{l}\text { Conducted } \\
\text { Experiment }\end{array}$ & $\begin{array}{l}\text { Presented } \\
\text { Results }\end{array}$ & $\begin{array}{l}\text { Compared Results } \\
\text { with previous study }\end{array}$ & $\begin{array}{l}\text { Claimed to Improve } \\
\text { Results }\end{array}$ & $\begin{array}{l}\text { Contributed to } \\
\text { knowledge }\end{array}$ \\
\hline [38] & $\mathrm{x}$ & $\checkmark$ & $\mathrm{x}$ & $\checkmark$ & $\checkmark$ & $\mathrm{x}$ & $\mathrm{x}$ \\
\hline [50] & $\checkmark$ & $\checkmark$ & $\checkmark$ & $\checkmark$ & $\checkmark$ & $\mathrm{x}$ & $\checkmark$ \\
\hline [3] & $\mathrm{x}$ & $\mathrm{x}$ & $\checkmark$ & $\checkmark$ & $\mathrm{x}$ & $\mathrm{x}$ & $\checkmark$ \\
\hline [5] & $\mathrm{x}$ & $\checkmark$ & $\checkmark$ & $\checkmark$ & $\checkmark$ & $\mathrm{x}$ & $\mathrm{x}$ \\
\hline [6] & $\mathrm{x}$ & $\checkmark$ & $\checkmark$ & $\checkmark$ & $\checkmark$ & $\mathrm{x}$ & $\checkmark$ \\
\hline [8] & $\mathrm{x}$ & $\checkmark$ & $\checkmark$ & $\mathrm{x}$ & $\mathrm{x}$ & $\checkmark$ & $\checkmark$ \\
\hline [9] & $\checkmark$ & $\checkmark$ & $\checkmark$ & $\checkmark$ & $\mathrm{x}$ & $\mathrm{x}$ & $\mathrm{x}$ \\
\hline [10] & $\mathrm{x}$ & $\checkmark$ & $\checkmark$ & $\checkmark$ & $\mathrm{x}$ & $\mathrm{x}$ & $\checkmark$ \\
\hline [13] & $\mathrm{x}$ & $\mathrm{x}$ & $\checkmark$ & $\checkmark$ & $\mathrm{x}$ & $\mathrm{x}$ & $\mathrm{x}$ \\
\hline [17] & $\checkmark$ & $x$ & $x$ & $\mathrm{x}$ & $x$ & $\mathrm{x}$ & $\checkmark$ \\
\hline [21] & $\checkmark$ & $\checkmark$ & $\checkmark$ & $\checkmark$ & $\mathrm{x}$ & $\checkmark$ & $\checkmark$ \\
\hline [63] & $\mathrm{x}$ & $\checkmark$ & $\checkmark$ & $\checkmark$ & $\mathrm{x}$ & $\mathrm{x}$ & $\mathrm{x}$ \\
\hline [29] & $\mathrm{x}$ & $\checkmark$ & $\checkmark$ & $\checkmark$ & $\mathrm{x}$ & $\checkmark$ & $\checkmark$ \\
\hline [62] & $\checkmark$ & $\mathrm{x}$ & $\checkmark$ & $\checkmark$ & $\mathrm{x}$ & $x$ & $\checkmark$ \\
\hline [47] & $\mathrm{x}$ & $\mathrm{x}$ & $\mathrm{x}$ & $\mathrm{x}$ & $\mathrm{x}$ & $\mathrm{x}$ & $\checkmark$ \\
\hline [48] & $\checkmark$ & $\checkmark$ & $\checkmark$ & $\checkmark$ & $\checkmark$ & $\checkmark$ & $\checkmark$ \\
\hline [42] & $\mathrm{x}$ & $\checkmark$ & $\checkmark$ & $\checkmark$ & $\mathrm{x}$ & $\mathrm{x}$ & $\checkmark$ \\
\hline [51] & $\mathrm{x}$ & $\mathrm{x}$ & $\checkmark$ & $\checkmark$ & $\mathrm{x}$ & $\mathrm{x}$ & $\mathrm{x}$ \\
\hline [52] & $\checkmark$ & $\checkmark$ & $\checkmark$ & $\checkmark$ & $\mathrm{x}$ & $\mathrm{x}$ & $\checkmark$ \\
\hline [49] & $\checkmark$ & $\checkmark$ & $\checkmark$ & $\checkmark$ & $\mathrm{x}$ & $\checkmark$ & $\checkmark$ \\
\hline
\end{tabular}

As shown in Table $X$, there were many limitations and weaknesses in selected primary studies as no comparison was made with previous studies while experiments, Presented Results and Claimed to improve the results. Also, most of the works concerned with quality attributes of quality testing and prioritization and evaluation are related to selected primary study and RQ2 and RQ3.

As shown in the individual analysis, most of the works deal with the existing techniques using defined quality attributes to fulfil the requirements of RQ3 against quality parameters.

Therefore, during analysis we found that only 8 primary studies are comprehensive literature where 14 studies are proposing approaches or techniques, while 17 studies conducted experiments while testing web services and all 17 presented results. However, these results were not compared with previous studies which shows that every researcher continued with their experiments without contributing knowledge and only 5 studies compared the results with previous studies. Results with previous studies need more concentration in order to contribute knowledge to the study to improve the final results, where 5 studies claimed to improve approaches and techniques. 14 primary studies contributed knowledge and suggest some appropriate solution frameworks mentioned in Table X. It will help the testing industry to use existing techniques and approaches, models and frameworks. Fig. 11 shows the trend of the major contribution of quality studies which is self-explanatory according to Table X.

It is observed in Fig. 11 that there are some research trends such as comprehensive literature review, presented results, compared with previous studies and claimed to improve the results which were not satisfactory until now. Most of the articles recommended resolutions for current study, but still there is a need of evaluation study. Additionally, there is a need of assessment and standard research results in proposal. Further organizational research is needed to explore the real-time process in web service testing.

\section{Selected Quality Study Attributes}

Following is the detailed explanation of each quality attribute to make the web service testing better. There might be some other quality attributes for analysis, comprehensive literature review. According to our selected primary study, we are considering only quality attributes as shown in Table XI. To understand which study provides better quality for testing web service, the intention of the best solution for testers is to make the service better for the end user. 
The reasons for using different suggested methods, techniques, frameworks or tools under the defined quality attributes-based method has been defined in Table $X$ are as follows because web services are mixture of interfaces.

\section{E. Comparison of Research Findings}

Below is the comparison of previous studies and current study in comparison of research findings. A total eight literature reviews were compared with current study. According to the research parameters, results are expressed to address research questions for web service testing techniques with a solution. Parameters already stated in results of primary studies from 20 actual research paper's results are mentioned in Table $\mathrm{V}$ in tabular form. The symbol " $\checkmark$ " and "x" are specifically introduced for presence and absence, respectively, to present that the explicit studies address the constraints and previous studies to compare with current study.

Table XI showed the difference the comparison between previous studies literature reviews and SLR. It is shown that previous SLR's did not introduce all parameters, where this study selected common issues while testing or issues not discussed in previous studies. Some studies are providing details of experiments and techniques as a solution only against interoperability or reliability. Other studies provide solutions for security and performance only using existing techniques. It is need to cater to all existing quality parameters to make the quality of web service testing better.
From the results shown in Table XI, we have suggested following implications to make the web service quality better.

- The researcher will obtain awareness of different Web Service testing techniques in the testing environment.

- The solutions (testing, integrations and other testing events) so far established for web service testing. These resolutions use different frameworks, model, tools that will help testers in adopting while testing Performance, Interoperability, Maintainability, Reusability, Reliability, and Efficiency.

- Use of frameworks and tools increase the simplicity while proceedings in web service testing.

- The progressive and destructive effect of web service testing will support experts and organizations to implement suggested testing frameworks, models and tools.

- In web service testing, tools and frameworks support play an important role.

- Different testing techniques, models, frameworks play an important role in Web Service testing.

- The systematic literature review supports the testers to select frameworks, tools and models in testing conditions to establish web service testing in an easy and secure way.

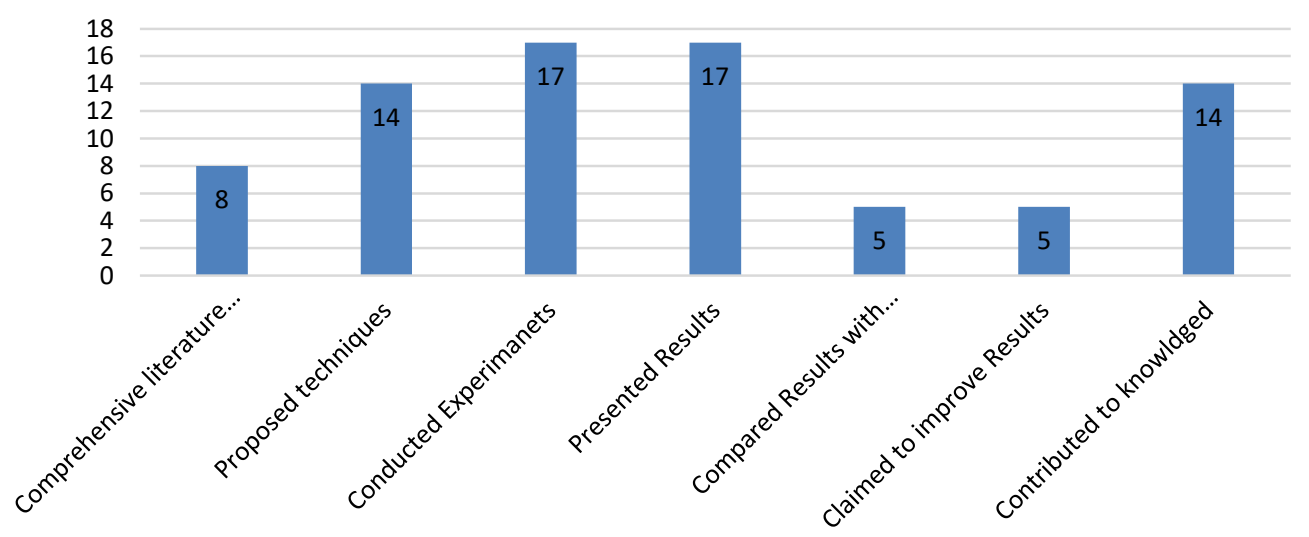

Fig. 11. Major Contribution of Quality Study.

TABLE. XI. COMPARISON BETWEEN PREVIOUS STUdIES AND CURRENT STUDY

\begin{tabular}{|l|l|l|l|l|l|l|l|}
\hline Overall Studies & Security & Performance & Interoperability & Maintainability & Reusability & Efficiency & Reliability \\
\hline$[38]$ & $\mathrm{x}$ & $\mathrm{x}$ & $\checkmark$ & $\mathrm{x}$ & $\mathrm{x}$ & $\mathrm{x}$ \\
\hline$[29]$ & $\mathrm{x}$ & $\checkmark$ & $\mathrm{X}$ & $\mathrm{x}$ & $\mathrm{x}$ & $\mathrm{x}$ \\
\hline$[6]$ & $\mathrm{x}$ & $\checkmark$ & $\checkmark$ & $\mathrm{x}$ & $\mathrm{x}$ & $\checkmark$ \\
\hline$[62]$ & $\checkmark$ & $\mathrm{x}$ & $\mathrm{X}$ & $\mathrm{x}$ & $\mathrm{x}$ & $\checkmark$ \\
\hline$[47]$ & $\mathrm{x}$ & $\mathrm{x}$ & $\checkmark$ & $\mathrm{x}$ & $\mathrm{x}$ & $\checkmark$ \\
\hline$[37]$ & $\mathrm{x}$ & $\checkmark$ & $\mathrm{x}$ & $\mathrm{x}$ & $\checkmark$ \\
\hline$[13]$ & $\checkmark$ & $\checkmark$ & $\checkmark$ & $\mathrm{x}$ & $\mathrm{x}$ & $\checkmark$ \\
\hline$[48]$ & $\checkmark$ & $\checkmark$ & $\checkmark$ & $\mathrm{x}$ & $\mathrm{x}$ & $\checkmark$ \\
\hline Current Study & $\checkmark$ & $\checkmark$ & $\checkmark$ & $\checkmark$ & $\checkmark$ & $\mathrm{x}$ \\
\hline
\end{tabular}




\section{THREAT TO THE VALIDITY IN RESEARCH}

The conclusion of systematic literature review research is consistent but there is a possibility of validity and bias threats for the duration of selection of primary study, conduct analysis or result phase of the SLR study [45]. Step of collection of primary study or exploration approach recognises maximum possible studies available in the literature by avoiding bias. There is possibility to skip some researches because of grey areas of study associated with literature such as contribution of solution techniques and relationship between primary study, testing techniques and testing levels. The research work is associated with multiple software testing communities, quality assurance, information system and simple object access (SOA) and web service testing. The method to identify the primary study is completed by considering internal validity, bias and external validity proposed and recommended by Cochrane Reviewers Handbook [42]. For further validation, the study is established on the implementation of an approach to promote the review. The transparency of the study will assist the researchers to evaluate the consistency of outcomes accurately.

The outcome of systematic literature review demonstrates that validation of the research is required in all kinds of support as shown in Table X. Assessment required some practical case studies and skilled reports in this capacity, which encourage researcher and testers.

\section{CONCluding ReMARKS AND Future PERSPECTIVE}

Web service testing is a significant issue that must be considered sensibly; testing must be broad, comprehensive and automated to all significant levels (unit, Black box, white box, regression, load, component, and system level testing). In order to evaluate the performance of web services, it is essential to evaluate the QoS (Quality of Service) attributes such as interoperability, reusability, auditability, maintainability, accuracy and performance to improve the quality of service. Different approaches, frameworks, models and tools among the main influences towards seven parameters, which are security, performance, interoperability, maintainability, reusability, reliability, and efficiency to evaluate better quality of web service testing. According to our primary study, $70 \%$ of web service testing is performed based on different testing techniques instead of frameworks or models to ensure better quality of web service testing. In the utilization of web services regarding different functional and non-functional requirements of the system, such framework and models provide better ways. Evaluation and testing at three main levels, such as end to end, service to service and interface to interface testing is important to ensure better quality of web services because of their extraordinary structure. This is because the most concerned aspect is the user who requires a better graphic user interface (GUI) with new change and provide compatibility, interoperability and performance with user machine. Further significant aspects that require attention may include traceability, compatibility, and complexity. Integrity and effectiveness should also be included to ensure better quality of web service. Furthermore, this study can be improved further by adapting Model based approaches; Semantic based approaches for existing and remaining quality parameters, increasing the quantity of selected primary studies by covering all the digital databases. Additionally, this study can be extended by including some extra testing techniques based on the following parameters: traceability, compatibility, complexity, scalability, auditability, effectiveness, integrity and inconsistencies in web service testing.

\section{ACKNOWLEDGMENT}

The authors would like to express their deepest gratitude to Universiti Teknologi Malaysia (UTM) and Ministry of Education Malaysia (MOE) for their financial support under the Research University Grant Scheme (Vot number Q.J130000.2516.19H64).

\section{REFERENCES}

[1] Kumar, A. K. Pandey, and M. Singh, "A novel testing framework for SOA based services," International Conference for Convergence of Technology, I2CT, Pune, India, 2014.

[2] M. I. P. Salas and E. Martins, "A Black-Box Approach to Detect Vulnerabilities in Web Services Using Penetration Testing," IEEE Latin America Transactions, no. 3, 2015.

[3] S. Jing and D. Yu-Yue, "Performance analysis of web service composition based on stochastic well-formed workflow," The International Conference on Networked Computing, Proceeding, Gyeongju, South Korea, 2010.

[4] R. Selvam and A. Senthilkumar, "Webservice based vulnerability testing framework," Proceeding of the IEEE International Conference on Green Computing, Communication and Electrical Engineering, ICGCCEE, Coimbatore, India 2014.

[5] S. Radhakrishna and M. Nachamai, "Performance inquisition of web services using soap UI and JMeter," 2017 IEEE International Conference on Current Trends in Advanced Computing, ICCTAC, Bangalore, India, 2018.

[6] S. Shridevi and G. Raju, "A literature survey on the performance evaluation model of semantics enabled web services," 2018.

[7] A. A. Nacer, K. Bessai, S. Youcef, and C. Godart, "A Multi-criteria Based Approach for Web Service Selection Using Quality of Service (QoS)," Proceedings IEEE International Conference on Services Computing, New York, USA, 2015.

[8] R. Casado, J. Tuya, and M. Younas, "An abstract transaction model for testing the web services transactions," Proceedings IEEE 9th International Conference on Web Services, ICWS, Washington, DC, USA, 2011.

[9] I. A. Elia, N. Laranjeiro, and M. Vieira, "ITWS: An extensible tool for interoperability testing of web services," Proceedings IEEE International Conference on Web Services, ICWS, Anchorage, AK, USA, 2014.

[10] R. Casado, J. Tuya, and M. Younas, "A framework to test advanced web services transactions," 4th IEEE International Conference on Software Testing, Verification, and Validation, ICST, Berlin, Germany, 2011.

[11] M. Silic, G. Delac, I. Krka, and S. Srbljic, "Scalable and accurate prediction of availability of atomic web services USA," IEEE Transactions on Services Computing, 2014.

[12] Z. Mansor and E. Edwin, "Issues, Challenges and Best Practices of Software Testing Activity," Proceedings of the 14th International Conference on Applications of Computer Engineering (ACE '15),Seoul, South Korea, 2015.

[13] S. Azzam, M. N. Al-kabi, and I. Alsmadi, "Werb Service Testing Challenges and Approaches," 2012.

[14] A. Mendoza and G. Gu, "Mobile Application Web API Reconnaissance: Web-to-Mobile Inconsistencies \& Vulnerabilities," 2018.

[15] S. P. Ma, C. Y. Fan, Y. Chuang, W. T. Lee, S. J. Lee, and N. L. Hsueh, "Using Service Dependency Graph to Analyze and Test Microservices," International Computer Software and Applications Conference, Japan, 2018.

[16] C. F. Liao, C. J. Cheng, K. Chen, C. H. Lai, T. Chiu, and C. Wu-Lee, "Toward A Service Platform for Developing Smart Contracts on Blockchain in BDD and TDD Styles," IEEE 10th International Conference on Service-Oriented Computing and Applications, SOCA, Kanazawa, Japan, 2017. 
[17] J. Wang, X. Bai, L. Li, Z. Ji, and H. Ma, "A Model-Based Framework for Cloud API Testing," 2017.

[18] N. Pande, A. Somani, S. Prasad Samal, and V. Kakkirala, "Enhanced Web Application and Browsing Performance through Service-Worker Infusion Framework," IEEE International Conference on Web Services (ICWS), San Francisco, CA, USA, 2018.

[19] X. Chen, Z. Ji, Y. Fan, and Y. Zhan, "Restful API Architecture Based on Laravel Framework," Journal of Physics: Conference Series, 2017.

[20] A. Andrews, A. Alhaddad, and S. Boukhris, "Black-Box Model-Based Regression Testing of Fail-Safe Behavior in Web Applications," Journal of Systems and Software, 2018.

[21] Z. Chen, L. Shen, and F. Li, "Exploiting Web service geographical neighborhood for collaborative QoS prediction," Future Generation Computer Systems, 2017.

[22] F. Besson, P. Moura, F. Kon, and D. Milojicic, "Bringing Test-Driven Development to web service choreographies," Journal of Systems and Software, 2015.

[23] S. Mehta, G. Raj, and D. Singh, "Penetration Testing as a Test Phase in Web Service Testing a Black Box Pen Testing Approach," in Smart Computing and Informatics: Springer, 2018.

[24] M. Khanna, N. Chauhan, and D. Sharma, "A Novel Approach for Regression Testing of Web Applications," International Journal of Intelligent Systems and Applications, 2018.

[25] K. Incki, I. Ari, and H. Sözer, "A survey of software testing in the cloud," in IEEE Sixth International Conference on Software Security and Reliability Companion, Gaithersburg USA, 2012.

[26] A. Souri, A. M. Rahmani, and N. Jafari Navimipour, "Formal verification approaches in the web service composition: a comprehensive analysis of the current challenges for future research," International Journal of Communication Systems, 2018.

[27] J. Hu, X. Chen, Y. Cao, and L. Zhu, "A Comprehensive Web Service Selection Algorithm on Just-in-Time Scheduling," 2016.

[28] A. Askarunisa, K. A. J. Punitha, and A. M. Abirami, "Black Box Test Case Prioritization Techniques for Semantic Based Composite Web Services Using," International Conference on Recent Trends in Information Technology (ICRTIT), Chennai, Tamil Nadu, India, 2011.

[29] J. B. De Souza Neto, A. M. Moreira, and M. A. Musicante, "Semantic Web Services testing: A Systematic Mapping study," Computer Science Review, 2018.

[30] M. Ficco and M. Rak, "Stealthy denial of service strategy in cloud computing," IEEE Transactions on Cloud Computing, 2015.

[31] A. L. Lemos, F. Daniel, and B. Benatallah, "Web service composition: a survey of techniques and tools," ACM Computing Surveys (CSUR), 2016.

[32] S. Segura, G. Fraser, A. B. Sanchez, and A. Ruiz-Cortés, "A survey on metamorphic testing," IEEE Transactions on software engineering, 2016.

[33] Z. U. Singhera and A. A. Shah, "Extended web services framework to meet non-functional requirements," Workshop proceedings of the sixth international conference on Web engineering - ICWE Tokyo, Japan, Japan, 2006.

[34] P. Jamshidi, C. Pahl, N. C. Mendonça, J. Lewis, and S. Tilkov, "Microservices: The journey so far and challenges ahead," IEEE Software, 2018.

[35] H. Rusli, S. Ibrahim, and M. Puteh, "Testing Web Services Composition: A Mapping Study," Communications of the IBIMA, 2011.

[36] D. Tosi and S. Morasca, "Supporting the semi-automatic semantic annotation of web services: A systematic literature review," Information and Software Technology, 2015.

[37] P. Moretto, P. Rossaro, S. A. MacArthur, and D. Truffelli, "Systems and methods to identify and classify performance bottlenecks in cloud based applications," ed: Google Patents, 2018.

[38] E. I. Nabil, "Specifications for Web Services Testing: A Systematic Review," World Congress on Services, New York, NY, USA, 2015.

[39] W. A. Cidral, T. Oliveira, M. Di Felice, and M. Aparicio, "E-learning success determinants: Brazilian empirical study," Computers \& Education, 2018.
[40] N. E. Ioini and A. Sillitti, "Open Web Services Testing," World Congress on Services, Washington, DC, USA, 2011.

[41] F. J. Barroso, J. H. Cass, M. R. Deckert, M. J. Saylor, and A. Skwersky, "Automatic detection of problems in a large-scale multi-record update system and method," ed: Google Patents, 2019.

[42] M. Rahman and J. Gao, "A reusable automated acceptance testing architecture for microservices in behavior-driven development," 9th IEEE International Symposium on Service-Oriented System Engineering, IEEE SOSE, San Francisco Bay, CA, USA, 2015.

[43] T. Zhang and Q. Yao, "An Approach of End User Regression Testing for Semantic Web Services," International Conference on Management and Service Science, 2011.

[44] I. Baldini et al., "Serverless computing: Current trends and open problems," in Research Advances in Cloud Computing: Springer, 2017.

[45] B. Kitchenham and S. Charters, "Guidelines for performing Systematic Literature reviews in Software Engineering," Engineering, 2007.

[46] H. Zhong, L. Zhang, and S. Khurshid, "TestSage: Regression Test Selection for Large-Scale Web Service Testing," in 12th Conference on Software Testing, Validation and Verification (ICST) Xi'an, China, China, 2019: IEEE.

[47] A. Tahir, D. Tosi, and S. Morasca, "A systematic review on the functional testing of semantic web services," The Journal of Systems \& Software, 2013.

[48] M. Bozkurt, M. Harman, and Y. Hassoun, "Testing Web Services : A Survey."

[49] C. Ye and H. A. Jacobsen, "Whitening SOA testing via event exposure," Transactions on Software Engineering, 2013.

[50] N. Antunes and M. Vieira, "Designing vulnerability testing tools for web services: approach, components, and tools," International Journal of Information Security, 2017.

[51] C.-s. Wu, "The Web Services Composition Testing Based on Extended Finite State Machine and UML Model," Fifth International Conference on Service Science and Innovation, Kaohsiung, Taiwan, 2013.

[52] V. Heorhiadi, S. Rajagopalan, H. Jamjoom, M. K. Reiter, and V. Sekar, "Gremlin: Systematic Resilience Testing of Microservices," Proceedings - International Conference on Distributed Computing Systems, Nara, Japan, 2016.

[53] P. Brereton, B. A. Kitchenham, D. Budgen, M. Turner, and M. Khalil, "Lessons from applying the systematic literature review process within the software engineering domain," 2007.

[54] A. Mendoza and G. Gu, "Mobile Application Web API Reconnaissance: Web-to-Mobile Inconsistencies \&amp; Vulnerabilities," 2018.

[55] S. Subashini and V. Kavitha, "A survey on security issues in service delivery models of cloud computing," Journal of network and computer applications, vol. 34, no. 1, pp. 1-11, 2011.

[56] C. William, D. Poshyvanyk, M. K. Moran, C. Eduardo, and B. Cardenas, "Development, Testing and Maintenance of Android Apps : Challenges, Tools , and Future Directions," IEEE/ACM 5th International Conference on Mobile Software Engineering and Systems (MOBILESoft), Gothenburg, Sweden, 2018.

[57] M. A. Jamil, M. Arif, N. Sham, A. Abubakar, and A. Ahmad, "Software Testing Techniques: A Literature Review," 6th International Conference on Information and Communication Technology for The Muslim World (ICT4M) Jakarta, Indonesia, no. November, 2016.

[58] W. Ha, "Reliability Prediction for Web Service Composition," pp. 7-10, 2017.

[59] M. J. Kargar and A. Hanifizade, "Automation of regression test in microservice architecture," 4th International Conference on Web Research, ICWR, Tehran, Iran, 2018.

[60] M. M. Eler, M. E. Delamaro, J. C. Maldonado, and P. C. Masiero, "Builtin structural testing of web services," Brazilian Symposium on Software Engineering ,Salvador, Bahia, Brazil, 2010.

[61] T. Masood, A. Nadeem, and S. Ali, "An Automated Approach to Regression Testing of Web Services based on WSDL Operation Changes," IEEE 9th International Conference on Emerging Technologies (ICET), Islamabad, Pakistan, 2013.

[62] S. Sim, "Formal Testing Approaches for Service-Oriented Architectures and Web Services : a Systematic Review * e Takeshi Endo." 